\title{
Exploring Textual Metafunction in Akachi Ezeigbo's The Last of the Strong Ones: A Gender-Based Analysis of Female Roles in Contemporary African Society
}

\author{
Léonard Koussouhon
}

Ecole Doctorale Pluridisciplinaire (EDP), "Espaces-Cultures et Développement”, Faculty of Arts and Humanities, FLASH, University of Abomey-Calavi /UAC, Bénin koussouhon@yahoo.fr

\section{Sévérin Mèhouénou}

Faculty of Arts and Humanities, FLASH, Laboratory for Research in Linguistics and Literature (LabReLL), University of Abomey-Calavi /UAC, Bénin mehouenous@gmail.com

\begin{abstract}
This article aims at exploring Systemic functional grammar with an emphasis on textual meaning, in Akachi Ezeigbo's The Last of the Strong Ones. Indeed, this is one of three meta-functions of language propounded by scholars like Halliday (1985a, 1989, 2004), Eggins (1994), Hasan (1996, 2009) for the study of language in terms of how it functions and how it is structured in a fictional / non-fictional text. The exploration of the grammar of textual meaning helps uncovering the deep messages conveyed in the selected extracts from the novel. In this regard this paper considers the selection of two extracts from the novel under study, thereafter applies the grammar of Theme / Rheme to them in the process of describing their meanings about the experiences, the social relationships between interactants as well as the rhetorical structure of their discourse. The very deep messages conveyed through the novel concern the colonial women and their changing roles in the society either they find themselves dealing with politics or as wives at home.
\end{abstract}

Keywords: Systemic Functional Linguistics (SFL), grammar of textual meaning, theme patterns, patriarchy, assertiveness, gender issues.

\section{INTRODUCTION}

A lot has been written and is still being written about the way men take advantage of their sexual advances to settle domination over women. In this, women are portrayed as ignorant, non-assertive, less able, less skillful and less intelligent in male-centered discourses. In this perspective, Koussouhon (2009b) has noted that female experience is excluded in early male-authored texts. This social injustice perpetrated against women by patriarchy has given rise to gender theories such as dominance and difference approaches pioneered by Lakoff (1975), Montgomery (1995), Tannen (1986, 1990, 1994) to name but a few. But when women made their entry into the arena of writing from the sixties onwards, they have seen literature as a means of righting all the wrongs against them. They reject women's subjugation, domination and exploitation in various ways. It is in this vein that Milicent Yengkangyi (2009: vii) in a move to scrutinize 'Feminism in Une si Longue Lettre by Mariama Bâ and Anowa by Ama Ata Aidoo' contends that: “...since the emergence of African women writers in the negro-African literature, there has been an important transformation on the image of the African woman". In fact, a handful of contemporary African female writers and male sympathizers as well have made a shift in their fictional oeuvres from the phallocentric perspective to the woman-centered perspective or to a blend of both, otherwise called the human-centered perspective. One of these writers is Akachi Ezeigbo, a contemporary Nigerian female writer.

This study then surveys Akachi Ezeigbo's alignment along this trajectory and examines how she portrays, in her novel, assertive female characters that launch real fights against patriarchy and patriarchal prejudices so as to allow them have a say in the society. In this article, we attempt to apply the grammar of textual meaning to two excerpts extracted from Akachi Ezeigbo's The Last of the Strong Ones in order to pinpoint the author's new perception about female gender formerly dimmed by writings before sixties. The discussion deriving from the analyses will eventually reveals how 
Akachi Ezeigbo discloses the dialectical roles African women hold as an individual in the society and as a wife in their husband's house.

\section{LiterATURE REVIEW AND METHODOLOGY}

From previous works published in this field, SFL/SFG appears to be a useful analytic tool. Unlike other linguistic theories such as the Chomskyan theory, for instance, the SFG theory pays more attention to language (as a system and the way it functions) and culminates with establishing a relationship between language and social class in a given socio-cultural context. It is obvious from the foregoing that a text (written or spoken) is inextricably linked to a specific culture (Widdowson, 2004). Moreover, the same author contends that a text influences and is in turn influenced by the context surrounding its occurrence or production. Systemic scholars highlight three types of context, viz. context of culture (or genre), context of situation (or register) and context of ideology (Eggins, 1994).

Recently, some scholarly linguistic research works have been carried out on both fictional, real-life and non-fictional artefacts cf. Dooga, (2009); Koussouhon, (2009; 2009b); Cunanan, (2011); Koussouhon and Koutchadé, (2011); Treimane, (2011); Bilal, (2012); Koussouhon and Koukpossi, (2013); Koussouhon and Allagbé, (2013); Koussouhon and Dossoumou, (2014); Koussouhon, Akogbéto and Allagbé, (2014)..., etc. While some of these works explore such grammatical aspects as Transitivity, Mood and Theme which realise such semantic dimensions as Ideational/Experiential, Interpersonal and Textual Meanings or Metafunctions in texts, others are practically devoted to the exploration of contextual properties as Field, Tenor and Mode which lexico-grammatically enact the context (cultural, situational and ideological) within which patterns of meaning are negotiated in texts. To the best of our knowledge, none of these previous scholarships has explored the Textual Metafunction in Akachi Ezeigbo's The Last of the Strong Ones.

The methodology chosen to carry out this study follows the principles of the qualitative method paradigm. In the process, the extracts have been selected from the novel, analyzed through the foregrounding of the various topical (unmarked/marked), textual, interpersonal, structural and multiple themes developed in the fictional text. The findings of the analysis are summarized and distributed in a table in order to facilitate their discussion. The keys used for the analyses read as follows: [Th: Utp $]=$ Unmarked topical theme; $[\boldsymbol{T h}: \mathbf{M t p}]=$ Marked topical theme; $[\boldsymbol{T h}:$ Str-tp $]=$ Structural topical theme; $[\boldsymbol{T h}: \boldsymbol{t} \boldsymbol{x}]=$ Textual theme; $[\boldsymbol{T h}: \mathbf{I n t}]=$ Interpersonal theme; $[$ Th: $S t r]=$ Structural theme; $[\mathbf{T h}: \mathbf{m p l}]=$ multiple themes.

\section{RESULTS}

See full texts of the practical analysis of theme patterns in appendices.

The identification of the themes in each extract has been done in line with the keys suggested by scholars (Koussouhon \& Allagbé, 2013; Koussouhon \& Dossoumou, 2014) and systemicists especially Suzanne Eggins (2004).

Table 1 below displays the occurrence of the various theme types and their percentage in each of the two extracts

Table1. Distribution of Theme types in the extracts

\begin{tabular}{|c|l|c|c|c|c|}
\hline \multicolumn{2}{|c|}{ Theme types } & \multicolumn{2}{c|}{ Extract 1 } & \multicolumn{2}{c|}{ Extract 2 } \\
\hline \multirow{3}{*}{ Topical } & 101 & $63.12 \%$ & 99 & $61.87 \%$ \\
\cline { 2 - 6 } & Unmarked & 13 & $08.12 \%$ & 22 & $11.89 \%$ \\
\cline { 2 - 6 } & Marked & 07 & $04.37 \%$ & 04 & $02.16 \%$ \\
\hline \multicolumn{2}{|c|}{ Structural } & 28 & $17.5 \%$ & 28 & $15.13 \%$ \\
\hline \multicolumn{2}{|c|}{ Textual } & 09 & $05.62 \%$ & 11 & $05.94 \%$ \\
\hline \multicolumn{2}{|c|}{ Interpersonal } & 02 & $01.25 \%$ & 21 & $11.35 \%$ \\
\hline \multicolumn{2}{|c|}{ Structural } & $\mathbf{1 6 0}$ & $\mathbf{1 0 0 \%}$ & $\mathbf{1 8 5}$ & $\mathbf{1 0 0 \%}$ \\
\hline
\end{tabular}

The table above gives an account of the statistic distribution of theme types in the two extracts. As the practical thematic analysis exudes, the thematic analysis carried out in the extracts revealed a preponderance of topical themes in both extracts (i.e. $75.61 \%$ in extract 1 and $75.92 \%$ in extract 2). This entails that the extracts are over-topicalized. The over-topicalization of the extracts under study 
entails that the issues discussed therein are topical and burning. The textual themes rank second in both extracts followed by interpersonal themes in the first and structural themes in the second. Structural themes in extract 1 and interpersonal themes in extract 2 come in last position. This ranking gives room for a critical analysis of the extracts.

\section{Discussion of the SAlient Linguistic Features of THE EXTRaCtS}

\subsection{Critical Discussion of the Findings from Extract 1}

The theme identified in this extract reveals that it includes a total of 160 themes. Out of this figure, one hundred and one (101, viz, $75.61 \%)$ are topical whatever their positions of unmarked, marked or structural. Twenty-eight (28, viz $17.5 \%)$ are textual; while nine (09, viz $05.62 \%)$ are interpersonal. The lowest number of theme identified is that of structural (02, viz $01.25 \%)$. The thematic choice made by the author gives account of the way the main characters get organized to go against the colonizers' imperial progression on their land. As a matter of fact, some names such as Ejimnaka, Onyekozuru, Chieme, Chibuka, some collective nouns such as Obuofo, Oluada, Kosiri to name but a few and some pronouns such as 'we', 'they' in extractl account for most of the thematic distribution in the text. 'We' refers to the oluada, the top women representatives who meet at Ejimnaka's house to decide about the attitude to be taken at their meeting with Obuofo (men representatives), and 'they' refers to the warrants chiefs whose presence beside the white man is seen as an act of betrayal. Kosiri may sound strange but it connotatively refers to the white man in general. This foregrounds that there is a clash between two people from different cultural backgrounds, which gives rise to the issues of violence, aggression, dominance and resistance demonstrated by the author through the novel and noted within the females' idiolects. This is what explains the paucity of interpersonal themes in the extract. The predominance of textual themes in the extract suggests that the clauses are combined in a way to make a faithful account of the events.

By and large, this extract reveals women's participation in the political life of their country. In fact, to avoid being merely decorative objects besides men, Umuga women get themselves into a wellstructured association in vein of contributing to the political development of their country. If the whole chapter is considered, it would be read that two important decisions have been taken at the meeting. The first one is that: ".......oluada agreed to participate more intensively and vigorously in obuofo and continue to represent the women actively in the political body" (p.12). The second one is that: "Oluada refused to cooperate with any power or anyone that planned to undermine the culture, the traditional judicial system and the economic well-being of Umuga."(p.12). These idiolects testify to women's crusade against their traditional roles in the society by rivaling with men on political ground.

\subsection{Critical Discussion of the Findings from Extract 2}

It has been identified in this extract a total number of 185 themes. Out of this number, 125 (i.e.75.92\%) are topical themes ranking first, 28 (.i.e.15.13\%) are textual themes, 21 (i.e. $11.35 \%$ are structural themes and 11 (i.e. $05.94 \%$ ) are interpersonal themes.

The use of the pronouns "I", "he", "they" in thematic position in this extract implies that there is a shift in the course of narration. "I" refers to Chibuka, the one narrating her own marital experience, "he" to her husband, Iheme, "you" refers to the other oluada members listening to her marital experience, and "they" to her parents. It is then clear that we are no longer in presence of the narration of the cultural clash between Umuga people and the Kosiri but the narration of the ups and downs of marital life. The recurrent used of the pronoun "I" serving as the point of departure of most clauses in this text suggests that most of what is said is about Chikuba. She is the one that is listened to and the listeners' attention is required. This strategy used by the author goes back to the old days when some middle-aged people display their folksy wisdom to pass on audience cultural and traditional values through folk tales to educate young ones. This technique shows the linguistic complexity used by the author in the novel which draws all its artistic value from the recollection of past events. The relationship to the previous extract is that the author makes a breach into the life of oluada to disclose the readers what marriage used to be in Africa before the arrival of the colonizers and how women were treated within the couple. The analysis made of all this suggests that colonization has not brought much change to women's already devastating situation. 
All in all, we are here in presence of a female character that contributes to the political life of her country through oluada but has been ill-treated by her husband in the past. This is a paradox associated with female gender in African society. While African women re-create or re-examine themselves in the light of political and economic independence, their marital situation remains controversial and depends on the man they are associated with. By getting into association, they make themselves instruments to be used to mobilize people on this way of victimizing women within marital settings.

\section{SUMMARY AND CONCLUSION}

To sum up, this article has used systemic functional grammar as the backbone to shed light on the way the author encodes meanings in her novel. The practical analysis carried out therein has explored the grammar of textual meaning in two extracts. The data stemming from the linguistic description has been discussed against the backdrop of African feminist guidelines. As the analysis exudes, the almost equal proportion of occurrence of interpersonal themes in the two extracts $(05.62 \%$ and $05.94 \%)$ is indicative of how gender equity should be henceforth observed in social interactions, including workload sharing, between men and women. Womanhood should no longer be regarded as a handicap preventing women from accessing high-level professional and social positions and subsequently inflicting some predicaments on them. Nor shall it be validated against some outdated, de-facing and degrading social schisms. This has been profusely illustrated by the recurrent use of names, ad hoc description and recoverable references in the selected extracts.

The identification of theme types corroborates the message the author conveys through the novel. In the light of the linguistic application carried out in the novel drawing on the grammar of textual meaning, our study displays the dominance of topical themes in both extracts. This linguistic salient feature displays a number of elements in thematic position and as such foregrounds the message conveyed through the novel. The organization of the message has allowed us to understand that language has been structured to make meanings about women during the colonial period, on the one hand, and the issues related to their marital status, on the other hand. In fact, during that period, women have taken active part in the resistance against the colonizers' settlement besides men so as to preserve the distortion of Umuga cultural values. Here we see some assertive women with dominant speech features committed to contribute to the political life of their natal home. The gender roles assigned is reversal to women's language characterization Lakoff identifies as being unassertive, tentative or trivial. However, the way these female leaders are treated within couple life implies that African feminism still has battles to win. African female writers have recently understood that African feminism need not be oppositional to men (Ogundipe Leslie, 1994:225). Here women are seen in a position of subordination with a possibility of rejecting men's domination over them or negotiating to unburden and off-load those patriarchal prejudices weighting over them. It is then to be understood that African female writers are taking optimistic view about change by creating Nego-feminism (Nnaemeka Obioma, 1999) or Snail-sense feminism (Akachi Ezeigbo, 2002) which calls for negotiation, cooperation and dialogue with patriarchy for an improvement of women's conditions not only in the society but also in their marital settings.

\section{REFERENCES}

\section{Books}

Coates, J. \& Cameron, D. (eds) (1988). Women in their Speech Communities. London: Longman.

Del, J. (1970). Social linguistics and literacies: Ideology in discourses. Philadelphia: Falmer.

Eggins, S. (2004). An Introduction to Systemic Functional Linguistics. $2^{\text {nd }}$ Edition, NewYork: Continuum.

Ezeigbo, A. (2006). The Last of the Strong Ones. Lantern Books Literamed Publications (Nig.) Ltd.

Ezeigbo, A. (2005). House of Symbols.Lantern Books. Literamed Publication (Nig) Ltd.

Halliday, M.A.K. (1994). Introduction to Functional Grammar, Second Edition. London:Edward Arnold.

Holmes, J. (2001). An Introduction to Sociolinguistics. London: Longman. 
Exploring Textual Metafunction in Akachi Ezeigbo's The Last of the Strong Ones: A Gender-Based Analysis of Female Roles in Contemporary African Society

Lakoff, R. (1975). Language and Woman's Place. New York: Harper \& Row.

Matthiessen, C.M.I.M. (1995). Lexico-grammatical Cartography: English Systems. Tokyo: International Language Science Publishers.

Montgomery, M. (1995). An Introduction to Language and Society. $2^{\text {nd }}$ edition. New York:Routledge.

Ogundipe, L. M. (1994). Re-Creating Ourselves: African Women and CriticalTransformations. Trenton and New Jersey: Africa World Press, Inc..

Sunderland, J. (2006). Language and Gender: An Advanced Resource Book. London: Routledge.

Tannen, D. (1990). You Just Understand, Women and Men in Conversation. New York: Ballantine Books.

Articles

Halliday, M.A.K. (1970). "Descriptive Linguistics in Literary Studies".In Essays in Modern Stylistics. D.C. Freeman (eds) (1981). London and New York: Methuen

Koussouhon, L. \& Dossoumou, A. (2014)."Lexico-Grammatical Analysis of Yellow-Yellow by Kaine Agary with a Focus on Experiential and Textual Meanings". In Mediterranean Journal of Social Science; Vol. $5 \mathrm{~N}^{\mathrm{o}} 23$, pp. 2430-2438.

Koussouhon, L. \& Allagbé, A. (2013). “The Lexicogrammar of Chimamanda Ngozi Adichie's Fiction: A Systemic Functional Contribution. In Langage \& Devenir $\mathrm{N}^{\mathrm{o}} 22,1^{\mathrm{er}}$ Semestre 2013, pp. 1944.

Koussouhon, L. (2013). "Linguistics-Oriented Literary Appreciation: How has it Fared thus Far?" In Particip’ Action, Vol.5 - No 1, Janvier 2013, pp.159-177.

Koussouhon, A. L. (2009b). "Male-dominating Language Patterns and Assertive Female Idiolects in

Anglophone African discourse”, in Langage \& Devenir, Revue Semestrielle. Pp. 17-31.

Nnaemeka, O. (1999). "Nego-feminism: Theorizing, Practicing, and Pruning Africa's Way". Journal of Women in Culture and Society, Vol. $29 \mathrm{~N}^{\circ}$ 2.The University of Chicago Press, 2003.

Oloko, P. (2008). "Old Stories, New Plots: Understanding the Poetics of 'Pro-Colonialism'. In Akachi Adimora- Ezeigbo's The Last Of The Strong Ones". In LARES: A Journal of Language and Literary Studies, Vol 16, $\mathrm{N}^{\mathrm{0}} 1$ and 2, pp. 17-31.

Yengkangyi, M. (2009). "Feminisme dans Une Si Longue Lettre de Mariama Bâ et dans Anowa d'Ama Ata Aidoo". A Dissertation presented to the Faculty of Social Sciences in Kwame Nkruma University of Science and Technology, Kumassi

\section{Appendices}

\section{Theme analysis in extract 1 (pp.4-8)}

Before dawn [Th: Mtp], we [Th: Utp] had gathered at Ejimnaka's house for a meeting of oluada. The message dispatched to each of us [Th: Utp] had been urgent and unambiguous. We [Th: Utp] had been told to be there by the first cockcrow. We [Th: Utp] were the first to arrive, my fellow observer and myself. Ejimnaka [Th: Utp] was already up and about, arranging chairs in front of her hut. We [Th: Utp] could not see her face clearly in the twilight. The prevailing dimness [Th: Utp] was still pervasive. However [Th: tx], we [Th: Utp] recognized her figure. Its solidity and comeliness [Th: Utp] arrested our attention. Though [Th: tx] she [Th: Utp] was middle-aged, she [Th: Utp] had the figure of a younger woman.

“Dee Nne," we [Th: Utp] greeted, accepting the chairs she offered.

"How [Th: Utp] are the children?"' she [Th: Utp] asked.

The arrival of Onyekozuru at that moment [Th: Utp] diverted our attention. Again [Th: Mtp], we [Th: Utp] exchanged greetings and [Th: tx] enquired after one another's families. Aziagba, Ejimnaka's daughter, [Th: Utp] approached from another hut, adjoining her mother's. Tall, dark-skinned and graceful [Th: Mtp], she [Th: Utp] was a replica of Ejimnaka, but slightly taller. 
"Dee Nne," she [Th: Utp] said, encompassing us with her greeting. She [Th: Utp] was carrying a water-pot.

“Aziagba [Th: Int], how [Th: Utp] are your children?" The question [Th: Utp] came from three pleasant voices, asking after her three little ones. Aziagba [Th: Utp] could not decide whom to answer first. In mild confusion [Th: Mtp], she [Th: Utp] turned to Onyekozuru - the oldest of us -and [Th: tx] her reply in that direction [Th: Utp] was adjudged enough for everyone.

"Aziagba [Th: Int], I [Th: Utp] can see you are going to fetch water," Ejimnaka [Th: Utp] said, pointing to the pot. She [Th: Utp] sat with her back resting on the door of the hut. "Who [Th: Utp] is going with you? I hope [Th: Int] you [Th: Utp] are not going alone?"

"Nne, I [Th: Utp] am not going alone," Aziagba [Th: Utp] reassured her. "Ebehara and Onugo [Th: Utp] asked me to call them when [Th: tx] I [Th: Utp] am ready."

She [Th: Utp] positioned the pot on her head and [Th: tx] titled it fully so that [Th: tx] it [Th: Utp] lay on its side. She [Th: Utp] walked away, her right hand grasping delicately the gaping mouth of the pot to prevent it from falling.

"'You [Th: Utp] did well to ask,"' Onyekozuru [Th: Utp] said, after a while. “'One [Th: Utp] hears all kinds of stories about things that [Th: str-tp] happen to people who [Th: str-tp] go to Agwazi early in the morning."

"Who [Th: Utp], in Umuga [Th: Mtp], has not heard the stories?"' Ejimnaka [Th: Utp] shrugged her shoulders. "Ever since the day that [Th: tx] kosiri and his escorts [Th: Utp] entered Umuga from Akwaihedi, and [Th: tx] camped in the sacred forest of Agwazi, our water goddess, the stream [Th: Utp] has not been the same. Danger [Th: Utp] pervades the place and the life of anyone who [Th: strtp] goes there is threatened. Agwazi's anger [Th: Utp] has remained unabated."

"Who [Th: Utp] can blame the goddess?" asked Onyekozuru. "What [Th: Utp] did kosiri and his servants not do to Agwazi, her sacred forest and the stream? First [Th: Mtp], they [Th: Utp] fetched water from the stream, using iron cups and metal pots. Then [Th: Mtp], they [Th: Utp] caught the sacred fish and [Th: tx] cooked them with firewood gathered from the forest. Even [Th: Mtp] the sacred monkeys in the forest [Th: Utp] were not spared..."

Chieme and Chibuka [Th: Utp] arrived as [Th: tx] Onyekozuru [Th: Utp] was speaking and [Th: tx] greeted us. They [Th: Utp] had overheard what [Th: str] was said and [Th: tx] their faces immediately [Th: Utp] assumed a disdainful and angry mien, demonstrating their mutual contempt for kosiri.

"The strangers who [Th: Utp] came to desecrate our home and steal our land!" Chieme [Th: Utp] cried, tossing her chair into a more comfortable position. "The land of our fathers, Umuga [Th: Utp], will pursue them, relentlessly, until [Th: tx] they [Th: Utp] are pushed into the Great River which [Th: str-tp] they [Th: Utp] crossed to get here."

"Kosiri [Th: Utp] have brought us nothing but trouble," Chibuka [Th: Utp] put in, shaking her head. Her head-dress [Th: Utp], made from some coarse cloth, came undone, revealing her thick grey hair. She [Th: Utp] gathered the two loose ends from her shoulders and [Th: tx] quickly wound and [Th: tx] tied them round her head.

“One day [Th: Mtp], Kosiri [Th: Utp] will leave us in peace." Chieme [Th: Utp] drew a straight line on the ground to emphasize her utterance and [Th: tx] called on our ancestors to lend their support to her prayer. She [Th: Utp] concluded: "our people say [Th: Int] that [Th: tx] it [Th: Mtp] is the traveller who [Th: str-tp] must make the return journey and not the owner of the land. The power of the intruders [Th: Utp] is to be compared to the evening rays of the sun. Its intensity [Th: Utp] declines with the hour and [Th: tx] soon passes away. Yes [Th: Int], kosiri [Th: Utp] will depart one day."

"How right you are, daughter of Umuga," said Chibuka, turning to Chieme. The guest who turns rude and aggressive [Th: Utp] will surely leave the host's with a bruised body..."

Ejimnaka [Th: Utp], who [Th: str-tp] had been listening to the tirade against the white strangers, cleared her voice. "Daughters of our land [Th: Int], be patient. Please [Th: Int], let us [Th: Utp] calm down. Anger [Th: Utp] will lead us nowhere..."

"Those [Th: Utp] are wise words, Ejimnaka, but [Th: tx] it [Th: Mtp] is the heart's heaviness that [Th: str-tp] has given eloquence to the tongue." Onyekozuru [Th: Utp] sighed and [Th: tx] added, "But [Th: tx], I [Th: Utp] must not interrupt you. Please [Th: Int], continue." 
Ejimnaka [Th: Utp] had not shown any irritation at the interruption. Her words [Th: Utp] came flowing again, like the Agwazi river, placid and purposeful. "It [Th: Mtp] is time //we [Th: Utp] got to head of our talk. We [Th: Utp] are all here now. Dawn [Th: Utp] has arrived and [Th: tx] the day [Th: Utp] will not wait for anyone. The matter that brought us together [Th: Utp] is urgent and weighty. Let us [Th: Utp] not jump into the middle of it. Kosiri [Th: Utp] put an obstacle across the path of our life and [Th: tx] we [Th: Utp] shall not rest until [Th: tx] we [Th: Utp] clear it." She [Th: Utp] paused. "Do [Th: Int] I [Th: Utp] have your ears, daughters of our land?"

We [Th: Utp] had all been attentive; so [Th: tx] our response [Th: Utp] was forthright. " Our ears [Th: Utp] are open to you and [Th: tx] your words [Th: Utp] make sense", we [Th: Utp] chorused.

Ejimnaka [Th: Utp] sighed with satisfaction and [Th: tx] continued. "Obuofo [Th: Utp] will meet tomorrow to discuss the stubbornness and uncooperative attitude of Okwara, the warrant chief. This [Th: Utp] is //why [Th: str] we [Th: Utp] are meeting this morning to agree on common viewpoint. In our meeting with the men [Th: Mtp], tomorrow [Th: Mtp], we [Th: Utp] shall muster one voice. Oluada [Th: Utp] will stand together."

\section{Theme analysis in extract 2 (pp.132-136)}

After the celebration of the year of Isigwu - the year [Th: Mtp] I( unmarked topical theme) turned seventeen - my father [Th: Utp] told me //a suitor from our village [Th: Utp] was asking for my hand in marriage and [Th: tx] that [Th: str] he [Th: Utp] was acceptable to the umunna. I [Th: Utp] was not particularly happy at home because of the restrictions imposed on me by my parents, so [Th: tx] I [Th: Utp] did not object to being married. I [Th: Utp] had developed a deep love for children when [Th: str] I (unmarked topical) was in Agbaja, taking care of Eyiuche's children. If [Th: tx] marriage [Th: Utp] meant having my own children, then [Th: tx] I [Th: Utp] would look forward to it with cheer, I [Th: Utp] told myself as [Th: tx] I [Th: Utp] prepared for it.

Iheme, my suitor [Th: Utp], did not believe in prolonged marriage negotiations. He [Th: Utp] prepared to be in a hurry and [Th: tx] wanted to complete the ceremonies in the shortest time. However [Th: tx], my parents [Th: Utp] insisted that [Th: str] things [Th: Utp] had to be done according to custom. The First time [Th: Mtp] I [Th: Utp] was sent to him and his people for familiarization visit, I [Th: Utp] got to know that [Th: str] //both his parents [Th: Utp] were dead. He [Th: Utp] lived all alone in a big compound. His sister [Th: Utp] had to come from her own home to stay with us during my visit. She [Th: Utp] was like a watchdog, solely there to ensure that [Th: str] Iheme [Th: Utp] did not take me to bed.

Iheme [Th: Utp] was older than I; he [Th: Utp] could have been close to thirty, though [Th: tx] he looked younger because of his slender stature. When [Th: str] I [Th: Utp] saw him for the time, I [Th: Utp] got the impression that [Th: str] he [Th: Utp] was not pleasant. This [Th: Mtp] worried me because [Th: tx] I [Th: Utp] had hoped that [Th: str] the man I would marry [Th: Utp] would be playful and cheerful like Eyiuche's husband. Iheme [Th: Utp] was quiet and [Th: tx] rarely smiled. When [Th: str] I [Th: Utp] pointed this to Mother, she [Th: Utp] snapped:

"Does [Th: Int] it [Th: Mtp] matter whether [Th: tx] he [Th: Utp] smiles or not? Are [Th: Int] you [Th: Utp] going to eat smiles? Will [Th: Int] smiles [Th: Mtp] take care of you? What [Th: str] you [Th: Utp] need is a serious and healthy man who [Th: str-tp] can work hard and [Th: tx] take care of you."

I [Th: Utp] comforted myself with the thought that [Th: str] Iheme [Th: Utp] was a hard-working man. Everybody [Th: Utp] said so. I [Th: Utp] had noticed his large yam barn when [Th: str] I visited him. He [Th: Utp] had more yams in his barns than any of the men I knew except, of course, Igwe Anoka of Agbaja whose [Th: str-tp] yams [Th: Mtp] could fill a whole village.

Before [Th: tx] I [Th: Utp] left home, finally, Father [Th: Utp] told Mother to explain my new life to me.

"Akubata [Th: Int], take your daughter and [Th: tx] give her some pieces of advice. Let her [Th: Utp] not go to her husband's house and [Th: tx] prance about like a calf or throw her weight around. When [Th: str] Iheme [Th: Utp] speaks, she [Th: Utp] should not answer him back. You [Th: Utp] know your daughter as well as [Th: tx] I do; so [Th: tx] I do not have to tell you what to say." 
I [Th: Utp] was bathing my brother in front of the obi. Father [Th: Utp] looks at me intently at the end of his speech, as if [Th: tx] he [Th: Utp] was expecting me to say something. I [Th: Utp] said nothing. But [Th: tx] I [Th: Utp] was glad I [Th: Utp] would soon leave home. Soon [Th: Mtp] I [Th: Utp] would leave my parents' fault-finding behind me.

I [Th: Utp] arrived in my new home with relief. I [Th: Utp] was prepared to accept my husband and be good to him. For one thing [Th: Mtp] I [Th: Utp] did not want to have him complaining to my parents; that [Th: str-tp] would confirm their wrong opinion about me. Though [Th: tx] she [Th: Utp] had done her best to demolish the Agbaja influence in my life, I did not think [Th: Int] my mother [Th: Utp] was convinced she [Th: Utp] completely succeeded.

The real truth [Th: Mtp] was that [Th: str] I [Th: Utp] had left home too early and [Th: tx] my parents had not had me with them long enough for them to discover who [Th: str-tp] I [Th: Utp] really was. Consequently [Th: Mtp], they [Th: Utp] blamed Eyiuche and Agbaja for what [Th: str] they [Th: Utp] found unacceptable in me. But even at seven [Th: Mtp], before [Th: tx] I (unmarked topical) left home, I [Th: Utp] had been a bold child, spritely and pleasant. What [Th: str] Agbaja [Th: Mtp] did to me was to affirm my nature and direct its development. By trying to reverse my life [Th: Mtp], my parents [Th: Utp] only succeeded in putting my nature to sleep.

It [Th: Mtp] did not take me long to find out that [Th: str] Iheme [Th: Utp] was more difficult than [Th: tx] I [Th: Utp] had feared. He [Th: Utp] liked to keep to himself. If [Th: tx] I [Th: Utp] wanted to chat and laugh, he [Th: Utp] preferred to stay by himself in his obi, brooding. I [Th: Utp] had not met a more reticent and solemn character in my life. After several attempts to draw him out [Th: Mtp], I [Th: Utp] decided to be patient with him. Perhaps [Th: Mtp] this attitude [Th: Utp] explained the fact that [Th: str] it [Th: Mtp] took six months for me to find out he [Th: Utp] had had another wife before me. A neighbor, a young woman [Th: Utp] called Ihuoma, told me Iheme's first wife [Th: Utp] had died in childbirth, about two years earlier, and [Th: tx] that [Th: str] the little baby girl [Th: Utp] was taken away to be looked after by the dead woman's mother. I [Th: Utp] was speechless. How [Th: Utp] could Iheme hide this fact from me? Why [Th: Utp] did my parents not tell me? Did [Th: Int] they [Th: Utp] find this out during the customary enquiry made before [Th: tx] a marriage could be approved on both sides?

"My husband" [Th: Int], I [Th: Utp] addressed him later, in the evening. "Is [Th: Int] it [Th: Mtp] true you [Th: Utp] had a wife before me? Is [Th: Int] it [Th: Mtp] also true there [Th: Utp] is a little girl?"

It [Th: Mtp] took him long to reply. "Yes [Th: Int], you [Th: Utp] heard correctly." He [Th: Utp] did not say more.

But [Th: tx], why [Th: Utp] did you not tell me?", I [Th: Utp] asked in a pained voice.

"Did [Th: Int] your parents [Th: Utp] not tell you?", he [Th: Utp] asked in a mocking voice.

That night [Th: Mtp] I [Th: Utp] did not sleep well. What sort of man [Th: Utp] had I married? I [Th: Utp] asked myself again and again. What [Th: str] worried me most was his total self-sufficiency. He [Th: Utp] hardly talked to me. When [Th: str] it [Th: Mtp] was time for his meal, he [Th: Utp] ate quietly with good appetite. This way of living [Th: Utp] almost drove me mad. But [Th: tx] there [Th: Utp] was no sympathetic soul to confide in. My parents, least of all.

\section{AUTHOR'S BIOGRAPHY}

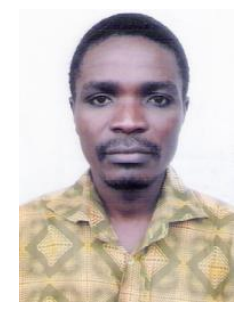

Sévérin Mèhouénou, Doctorate Student in Applied Linguistics FLASH/UAC, Benin; Member of Laboratory for Research in Linguistics and Literature (LabReLL)

Léonard Koussouhon, Full Professor (CAMES) of Applied Linguistics and African Anglo phone Literature 